\title{
Influence of Urban Landscapes to Microclimatic Variances in a Tropical City
}

\author{
Sharifah Khalizah Syed Othman Thania, \\ Nik Hanita Nik Mohamada, Sharifah Mastura Syed Abdullah ${ }^{\mathrm{b}}$ \\ aDepartment of Landscape Architecture, Faculty of Architecture, Planning and Surveying, \\ Universiti Teknologi MARA, Shah Alam, Malaysia \\ , bInstitute of Climate Change Studies, \\ Universiti Kebangsaan Malaysia, Bangi, Malaysia \\ khalizah81@gmail.com
}

\begin{abstract}
The outdoor spaces of hot-humid tropical cities are exposed directly to the high intensity of solar radiation. The increased heat gain contributes to the thermal discomfort in an urban environment. This study investigates the variability of outdoor air temperature produced on the different urban landscape morphology in Putrajaya. Results revealed that the temperature distribution is strongly influenced by the urban landscape morphology where significant temperature differences are observed at various urban areas. The findings could contribute toward a better understanding on the interrelationship between urban landscape morphology and its influence on the microclimatic atmosphere.
\end{abstract}

Keywords: Urban landscape morphology; outdoor temperature; thermal variation; tropical city

2398-4295 @ 2017 The Authors. Published for AMER ABRA by e-International Publishing House, Ltd., UK. This is an open access article under the CC BY-NC-ND license (http://creativecommons.org/licenses/by-nc-nd/4.0/). Peer-review under responsibility of AMER (Association of Malaysian Environment-Behaviour Researchers), ABRA (Association of Behavioural Researchers on Asians) and CE-Bs (Centre for Environment-Behaviour Studies), Faculty of Architecture, Planning \& Surveying, UniversitiTeknologi MARA, Malaysia.

http://dx.doi.org/10.21834/ajbes.v2i7.40 


\section{Introduction}

In tropical region, the rapid growth of urbanisation and socio-economic activities has modified its urban climate. This is due to the anthropogenic factors resulting from many physical and social urban activities. Further, the natural climatic condition of hot-humid tropics experiencing hot weather, high humidity and low wind velocity often leads to thermal discomfort in outdoor environment (Emmanuel and Johansson, 2006).

Several studies have shown large thermal variations especially during the daytime and high correlation between land use changes and temperature distribution in urban areas (Shaharuddin et al., 2010, Saaroni et al., 2000). These changes are closely related to the variation of urban land use and land cover pattern, urban roughness, physical and morphological factor; in which modify the energy balance of Earth's surface (Gartland, 2008:16, Emmanuel, 2005). This is eventually leads to the formation of Urban Heat Island (UHI) phenomenon. The urban factors that modify the surface energy balance and induce the formation of UHI phenomenon are summarised in Table 1.

Table 1. Urban characteristic that contribute to the formation of UHI phenomenon

\begin{tabular}{|c|c|c|}
\hline $\begin{array}{l}\text { Urban } \\
\text { characteristics }\end{array}$ & $\begin{array}{l}\text { Effect on the heat island } \\
\text { formation }\end{array}$ & $\begin{array}{l}\text { Effect on energy balance of } \\
\text { Earth's surface }\end{array}$ \\
\hline Lack of vegetation & $\begin{array}{l}\text { Increase solar radiation, air } \\
\text { temperature and humidity }\end{array}$ & Reduces evaporation \\
\hline $\begin{array}{l}\text { Large impermeable } \\
\text { surfaces }\end{array}$ & $\begin{array}{l}\text { Increase heat gain from } \\
\text { solar radiation }\end{array}$ & Reduces evaporation \\
\hline Urban materials & Increase thermal diffusivity & $\begin{array}{l}\text { Increased heat storage and } \\
\text { net radiation }\end{array}$ \\
\hline Urban geometries & Trap heat, slow wind speeds & $\begin{array}{l}\text { Increase net radiation and } \\
\text { reduces convection }\end{array}$ \\
\hline $\begin{array}{l}\text { Land uses and urban } \\
\text { activities }\end{array}$ & $\begin{array}{l}\text { Increase level of air pollution } \\
\text { and energy use }\end{array}$ & $\begin{array}{l}\text { Increased net radiation and } \\
\text { anthropogenic heat }\end{array}$ \\
\hline
\end{tabular}

(Source: Modified from Gartland, 2008)

The characteristics of landscape morphology that characterise cities and its interaction with local climate create a complex thermal behaviour of an urban area (Saaroni et al., 2000). This is even more experienced in hot-humid climates where it is hot throughout the year.

This characteristic presents a daunting challenge to relevant professionals in order to incorporate climate adaptive strategies into the design. However, understanding of the relationship between urban landscape and its influence on the microclimate could provide useful information in determining the important design aspects that could significantly contribute to achieve a comfortable thermal environment (Sharifah Khalizah et al., 2012). According to Shaharuddin (2012:13) and Brown (2011), the knowledge of the association 
between the urban landscape and its influence on climatic aspects can be utilised to create and modify a desired microclimatic impact.

The research objective is to provide understanding on the influence of urban landscape morphology and its impact to the climatic variance in hot-humid city. This is conducted through the investigation of microclimatic effect at various urban spaces in Putrajaya.

\section{Methodology}

\subsection{Study Area}

The study was carried out within the city of Putrajaya. The urban landscapes are distinctively enveloped by huge proportion of green spaces, man-made lakes and at the northern part of the city, a man-made wetlands is created by utilising the small rivers that run through the area. These elements give the unique features of Putrajaya urban landscape. Figure 1 shows the macro view of the study area. The climate of Putrajaya is categorised as typical hot and humid tropics where it is warm and sunny with uniform temperature, high humidity and light winds along with copious rainfall especially during the northeast monsoon.

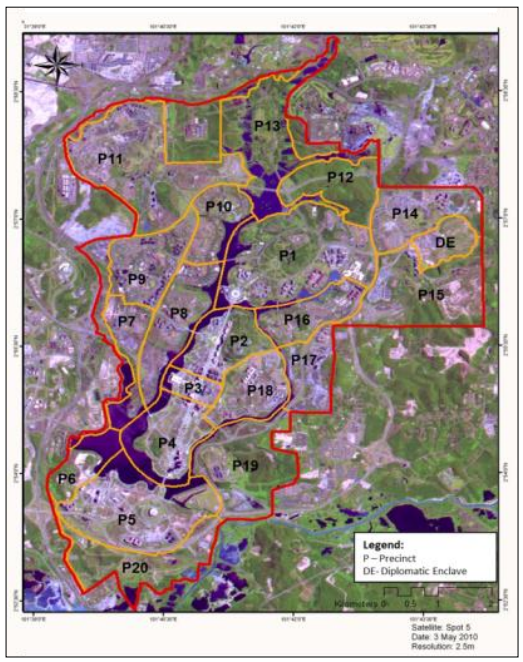

Figure 1: The view of the study area through SPOT-5 satellite imagery

Source: Courtesy of Malaysian Remote Sensing Agency, (2011) 


\subsection{Sampling design and selection of measurement sites}

There is no standard of variables to study the urban morphology in relation to meteorological aspects (Giridharan et al., 2007; Emmanuel and Johansson, 2006). Through literature survey, it is found that researchers usually identified the variables based on the specific characteristics and peculiarities of the study site in relation to the purpose of research. Therefore, based on the urban landscape and geographical features of Putrajaya, it is predetermined that the variables influencing the climate of the city would be the landscape morphology, urban geometry, land cover and land use activities. Thus, the variables of sampling points were selected to follow this criterion and adequately considered to represent the distinctive character of Putrajaya city. Fifteen point sources were selected for temperature measurements within Putrajaya city. The samples are disproportionally taken across all types of land use and land cover (i.e. built-up, green area and water bodies) and varies by dissimilarities of urban characteristics such as at different urban geometry and structures, surfaces, activities and others which are assumed to be representing the characteristics of the city. Figure 2 presents the general characteristics of selected sampling locations.

\subsubsection{Field measurement}

The outdoor air temperature $\left({ }^{\circ} \mathrm{C}\right)$ and relative humidity $(\mathrm{RH})$ measurements were conducted at $1.0 \mathrm{~m}$ above ground. Few researchers suggest that the ideal position in taking the ground measurement is as close to pedestrian height from the surface (Oke, 2006; Emmanuel and Johansson, 2006). Ground temperature measurements were acquired by using thermoanemometer model Lutron LM-8000. The field measurements of air temperature and relative humidity were taken from January to March 2012 between 1100 to 1400 hours (mid-afternoon) for two to three times a week (altogether 35 days of observation). The second measurements were conducted on 15 to 18 July 2012 within one-hour interval from 0900 to 1800 hours (Local Malaysian Time). Due to make simultaneous measurement, several field assistant were assigned to conduct the measurements. These measurements were taken on different weather occasions except for rain. This number of observation provided sufficient information to ascertain the highest and lowest temperature consistently recorded at the study area.

\subsubsection{Data analysis}

The measured data of air temperature and relative humidity at selected sampling points were averaged to represent mean daily values for the month of January to March 2012, and for July 2012. The mean values of temperature and relative humidity were then plotted in graphic diagrams to see the distribution of microclimatic variances at various urban landscapes. 


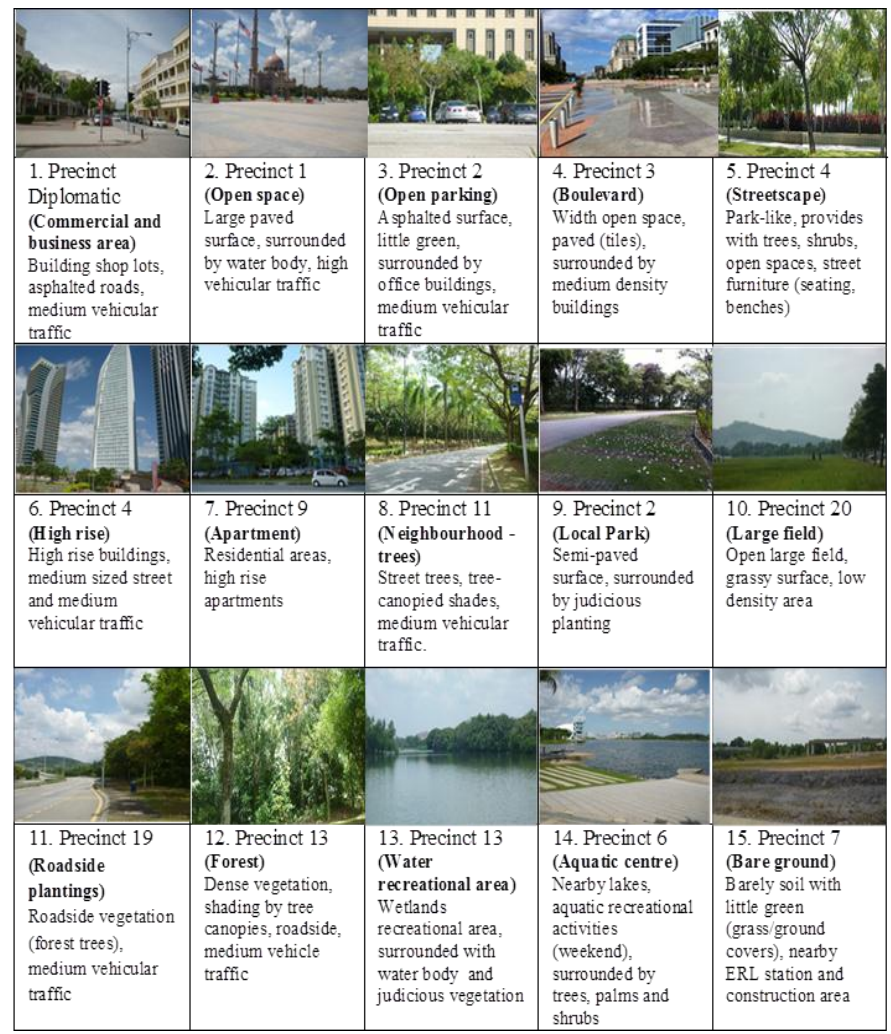

Figure 2: General characteristic of the sampling locations for temperature measurements

\section{Results and Discussions}

The distributions of temperature and relative humidity were varied at different urban landscapes by ranging on average of 32.5 to $39.0^{\circ} \mathrm{C}$ and 42.4 to $55.9 \%$ for the period of January to March 2012. In July 2012, the highest temperature averagely reached to $40.7^{\circ} \mathrm{C}$ and the hourly relative humidity was ranging between 41.8 to $75.1 \%$.

As plotted on the graphs in Figure 3, 4(a) and 4(b) accordingly, it can be clearly seen that the temperature and relative humidity produces contrasting readings where; in high temperatures, the relative humidity were at a low values whilst in low temperatures, the relative humidity recorded higher readings. This explained the influence of water vapour in ambient air temperature (Shaharudin et al., 2010) to function as a source of urban moisture content (Emmanuel and Johansson, 2006). 


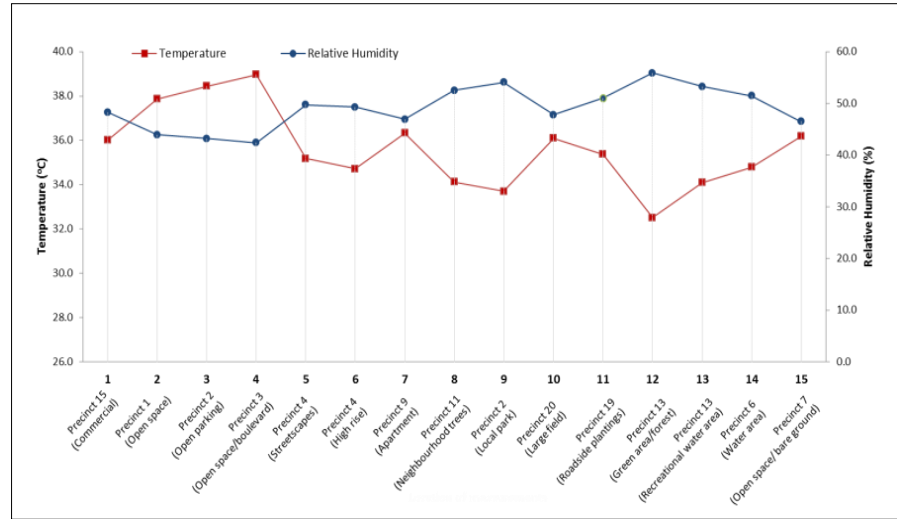

Figure 3: Average temperature and relative humidity in the study area for the period of January to March 2012

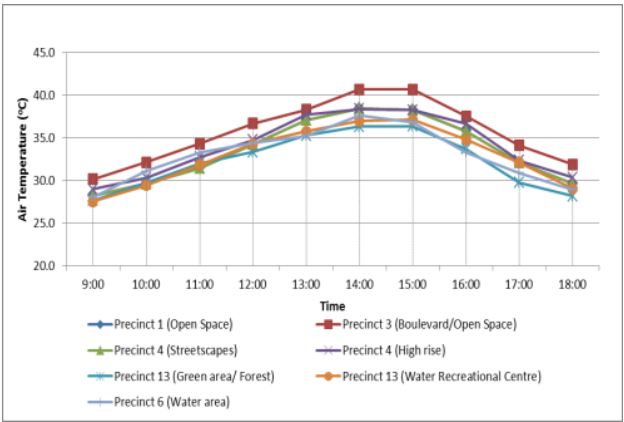

(a)

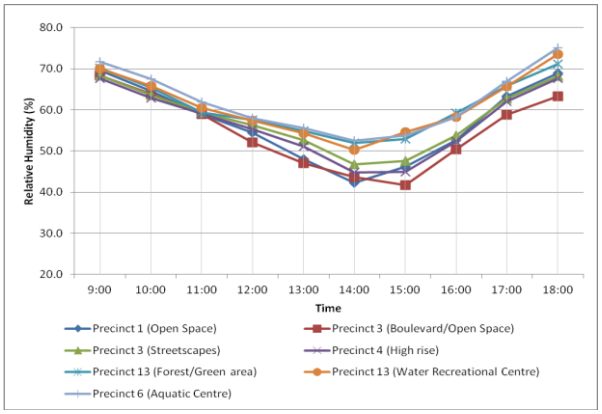

(b)

Figure 4: (a) Average daytime temperature in July 2012; (b) Average relative humidity in July 2012 
Further analysis by using simple linear regression was applied to test the relationship between two climatic parameters. From the analysis, it is demonstrated that the coefficient value of $R^{2}=0.9382$, meaning that it is almost perfect linear relationship between the two variables where the variation in $\mathrm{Y}$ axis (relative humidity) is explained by the variation in $\mathrm{X}$ axis (air temperature). From the graph (Figure 5), it is obviously seen that the relationship between temperature and relative humidity produced a significant negative correlation in which the high temperature commonly associated with low humidity. This means that the increase of ambient air temperature will reduce the moisture content (water vapour) in an urban environment and vice versa. The similar finding was observed in other tropical cities like Kuala Lumpur (Shaharuddin et al., 2011/2009) and Singapore (Wong and Yu, 2005).

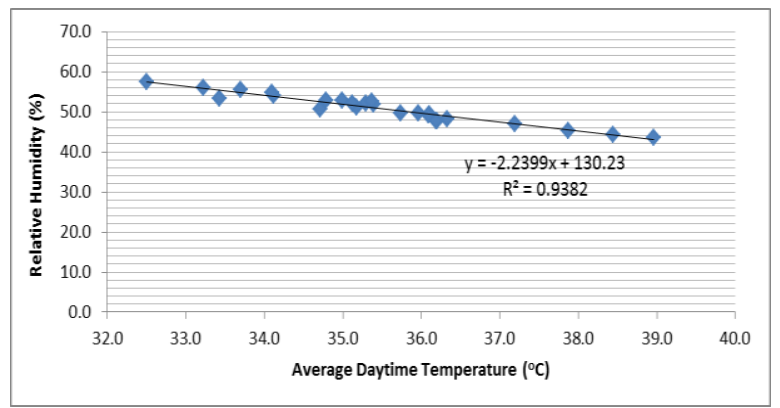

Figure 5: Correlation between temperature and relative humidity in the study area

During the measurements from January to March 2012 , the highest temperature $\left(39^{\circ} \mathrm{C}\right)$ was recorded at the boulevard area. Meanwhile, the green area (forestland) situated at the northern part of Putrajaya registered the lowest temperature $\left(32.5^{\circ} \mathrm{C}\right)$. In July 2012 , the boulevard still marked as the warmest area but the temperature increased by $1.7^{\circ} \mathrm{C}$. On the other hand, the forested area remained as the coolest sector with average temperature of $36.4^{\circ} \mathrm{C}$. Seemingly, as depicted in Figure $4(a)$, the results showed that the peak temperature was recorded in between 14:00 to 15:00 hours during the daytime and gradually decrease thereafter. The similar finding was also observed in Colombo city by Emmanuel and Johansson (2006).

\subsection{The variation of heat intensity at various urban landscape morphology}

The findings indicated that the urban landscape morphology influenced the variability of temperature and relative humidity in the study area and the impacts are clearly displayed through the thermal variances across different urban landscapes. As illustrated in Figure 6, the built-up areas that consist of commercial area (Precinct 15), administrative centres (Precinct 1 to 5) and residential area (Precinct 9) demonstrated highest temperature and lowest relative humidity while the wetlands forest and large water body of man-made lakes indicated vice versa. This finding indicated differences of heat intensity depending on the 
season. The average thermal differences recorded at selected sampling stations within the city for the period of January to March 2012 was recorded $6.5^{\circ} \mathrm{C}$ while in July 2012 , it was recorded $4.3^{\circ} \mathrm{C}$.

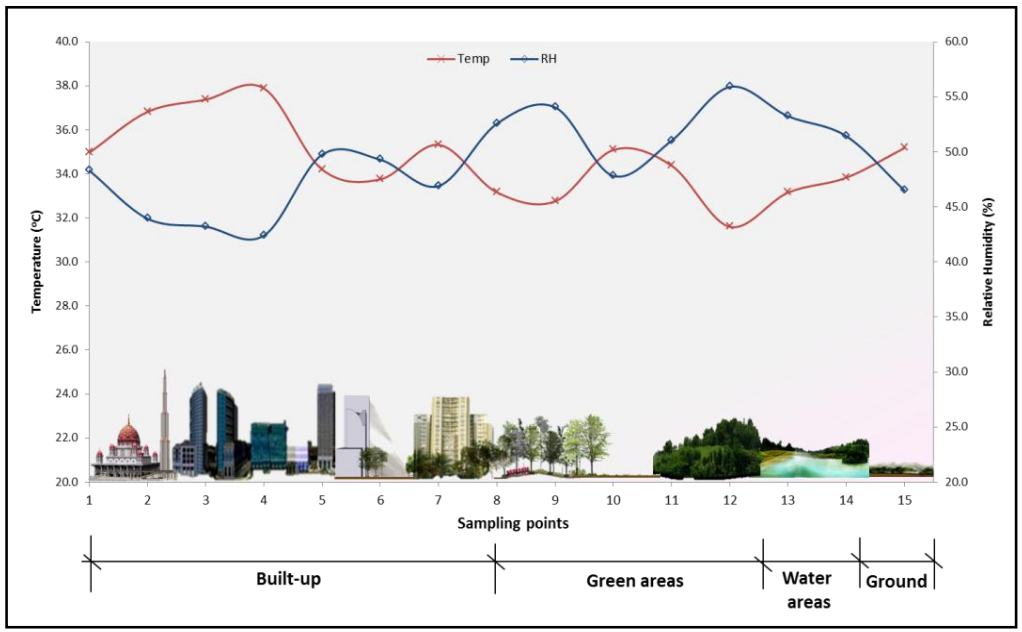

Figure 6: The sketch of climatic parameter variances within various urban landscapes morphology in Putrajaya city

Theoretically, the built-up area of paved surfaces and buildings are intensely warmed by the solar radiation and tend to store heat more rapidly than natural materials. Furthermore, the characteristics of the coolest spot which are densely planted with natural vegetation provide tree-canopy shading and located close to water areas. These characteristics have shown lower daytime temperature due to low capacity of thermal composition in the natural materials (Gartland, 2008: 18).

Apart from urban landscape form, the intra-urban thermal differences show remarkable variances between different urban surfaces. Figure 8 shows the temperature pattern that discerned on three generalized land cover types. From the findings, the thermal differences recorded at built-up, vegetated and near water body were ranging by the differences of 3.6 to $6.5^{\circ} \mathrm{C}\left(39.0^{\circ} \mathrm{C}>32.5^{\circ} \mathrm{C}<34.1^{\circ} \mathrm{C}\right)$. This indicates that the soft surfaces provide significant thermal benefits rather than built-up surfaces. However, the difference was small and almost no significant impact. The possible reason is maybe the natural or grassy surfaces are more capable to keep moisture in a longer duration, thus prevent the surface run-off unlike the impermeable surfaces of heavily built-up areas. 


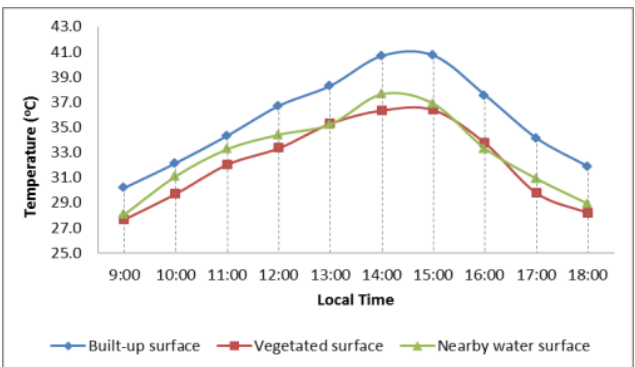

Figure 7: The temperature pattern within three generalised urban surfaces

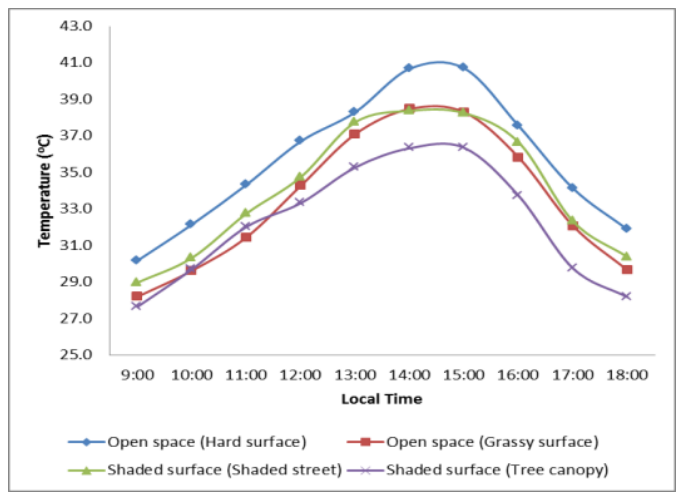

Figure 8: The temperature variance within open and shaded areas

Other than urban surfaces, significant temperature differences can be seen between shaded and open areas where the distribution of the outdoor temperatures were also influenced by shading factor. Typically, shaded areas recorded a consistent lower temperature readings compared to open spaces. In general, the open surfaces were recorded higher temperature and low humidity than the areas covered by tree canopies or shadowed by buildings. In this study, it was found that, despite the warm streets due to the openness of the boulevard area, the planted trees along street in Precinct 4 (streetscapes) provide some shades and reduce the temperature 2.8 to $4.3^{\circ} \mathrm{C}$ from the open surface. These findings confirm the conclusion made by Shashua-Bar and Hoffman (2000) and Rabiatul et al. (2012) that the shading effects provide by trees could provide significant comfort in thermal experience. Other than tree shading effects, the high rise buildings at Precinct 4 also casts shadows on the street, making the air temperature slightly cooler than the areas or surfaces without shading.

This indicates that to promote urban thermal comfort in hot-humid cities, the importance of design aspect that should be considered is to provide shading either through natural vegetation (trees) or by man-made shading devices. 
Overall, it was clearly indicated that the area with most greenery were the coolest sector while the architectural complex spaces with least greenery were the hottest sector in Putrajaya. Meanwhile, the area with modest urban structures and certain greenery such as the residential and neighbourhood area experienced average readings with small temperature differences. In addition, the covered surfaces either by tree canopies or shadow casts by orientation of the buildings was consistently provide shading and the air temperature were slightly lower than open surfaces. Other than that, the area nearby water body recorded lower temperature than built-up area, but slightly higher than vegetated surfaces. However, the measured data showed that the water areas fringed by dense vegetation (in this study at the wetlands water recreational centre) recorded a lower temperature than the water areas surrounded with sparse greenery. This supports the theoretical understandings that bioclimatic components have significant impact to the modification of urban temperature in built environment through evaporative cooling mechanism. Thus, based on the findings, it can be concluded that there were significant relationship between urban landscapes and the climatic variations where the morphology and characteristics of urban landscape have great influence to the microclimatic effects in the study areas. These results support the findings of previous researchers on the influence of urban design factors to the uprising temperature in the urban centre.

\section{Conclusion}

It is important to understand the landscape morphology and its interaction with the climate atmosphere before considering any design aspect in an urban development. Thus, the applied understanding on the influence of landscape and urban morphology could provide detailed information to planners and architects especially in determining the design aspects that promote outdoor thermal comfort. Although the understanding on landscape influences to the thermal environment could assist the practitioners in identifying good climate-design elements, nevertheless, achieving outdoor thermal comfort in hot-humid climate is not an easy operation. Therefore, such studies regarding hot-humid thermal comfort especially on the ability of natural vegetation and hydrological aspects to regulate local climate should be expand and further refined to gain better understanding on the specific climatic needs. With such knowledge, it could serves as preliminary strategies to outline the design schemes that can induce outdoor thermal comfort and climatic aspects that need to be further improved in future urban development of hot-humid tropical cities

\section{Acknowledgement}

This research paper is supported by a grant of Research Intensive Faculty (RIF) from Research Management Institute (RMI), Universiti Teknologi MARA (600-RMI/DANA/5/3/RIF (111/2012). 


\section{References}

Emmanuel, R., Johansson, E., (2006). Influence of urban morphology and sea breeze on hot humid microclimate: the case of Colombo, Sri Lanka. Climate Research, 30, 189 - 200.

Gartland, L., (2008). Heat Islands: Understanding and mitigating heat in urban areas. Earthscan, London, Sterling VA, (Chapter 2).

Giridharan, R., Lau, S.S.Y., Ganesan, S., Givoni, B., (2007). Urban design factors influencing heat island intensity in high-rise high-density environments of Hong Kong. Journal of Building and Environment, 42, 3669 - 3684.

Johansson, E., (2006). Influence of urban geometry on outdoor thermal comfort in a hot dry climate: A study in Fez, Morocco. Building and Environment, 41, $1326-1338$.

Malaysian Meteorological Department (2012). Northeast Moonsoon Report (November 2011), Kuala Lumpur Moonsoon Activity Centre. Retrieved on 21 September 2012 from www.met.gov.my.

Oke, T.R., (2006). Initial Guidance to Obtain Representative Meteorological Observations at Urban Sites, Instruments and Observing Method, Report No. 81, World Meteorological Organization, Geneva.

Rabiatul, A.N., Sabarinah, S.A., Azni, Z.A., (31 October - 2 November 2012). Adaptive outdoor thermal comfort at an urban park for the benefit of the present and future community. Procedia-Social and Behavioural Sciences, 68, $865-878$.

Shaharuddin, A. (2012). Mikroiklim Bandar: Perkembangan dan impak pulau haba bandar di Malaysia (In Malay). Penerbit Universiti Kebangsaan Malaysia.

Shaharuddin, A., Noorazuan, M.H., Yaakob, M.J., Kadaruddin, A., Muhamad, F.M. (2011). The effects of different land uses on the temperature distribution of a humid tropical urban centre. World Applied Sciences Journal, 13, 63 -68 .

Sharifah Khalizah, S.O.T., Nik Hanita, N.M., Sabrina, I., (31 October - 2 November 2012). Modification of urban temperature in hot-humid climate through landscape design approach: A review. Procedia-Social and Behavioural Sciences, 68, $439-450$.

Shashua-Bar, L., Hoffman, M.E., (2000). Vegetation as a climatic component in the design of an urban street: An empirical model for predicting the cooling effect of urban green areas with trees. Enery and Buildings, 31, 221 235.

Wong, N.H., Yu, C. (2005). Study of green areas and urban heat island in a tropical city. Habitat International, 29, $547-558$. 